\title{
Urban Strategies and Regional Development in the Alps
}

Author(s): Manfred Perlik and Paul Messerli

Source: Mountain Research and Development, 24(3):215-219.

Published By: International Mountain Society

DOI: http://dx.doi.org/10.1659/0276-4741(2004)024[0215:USARDI]2.0.CO;2

URL: http://www.bioone.org/doi/full/10.1659/0276-4741\%282004\%29024\%5B0215\%3AUSARDI $\% 5 \mathrm{D} 2.0 . \mathrm{CO} \% 3 \mathrm{~B} 2$

BioOne (www.bioone.org) is a nonprofit, online aggregation of core research in the biological, ecological, and environmental sciences. BioOne provides a sustainable online platform for over 170 journals and books published by nonprofit societies, associations, museums, institutions, and presses.

Your use of this PDF, the BioOne Web site, and all posted and associated content indicates your acceptance of BioOne's Terms of Use, available at www.bioone.org/page/terms_of_use.

Usage of BioOne content is strictly limited to personal, educational, and non-commercial use. Commercial inquiries or rights and permissions requests should be directed to the individual publisher as copyright holder. 


\section{Urban Strategies and Regional Development in the Alps

Nearly two-thirds of the population in the European Alps (which totals 14.2 million) lives in towns or periurban municipalities. We state that strong towns in the Alps are necessary to prevent outmigration. But these towns must be internally integrated with their hinterlands and externally integrated in supraregional networks to maintain the quality of life and contribute to regional economic growth.
This appears to be possible despite the differences that typify Alpine agglomerations, since both large and small towns have an internal and an external function; what differentiates them is the proportion between the two functions. Although these differences imply that possibilities for future development vary, some strategies may be generally valid for towns in the Alps.

\section{Urbanization of European mountain areas}

In densely populated Europe, large metropolitan areas have developed on the perialpine edges at the foot of the mountains on both sides of the Alps, while towns in the mountains have remained small or medium-size centers for the most part (Figure 1). This applies to the Alps as well as most other European mountains.

This pattern did not seem to be a problem in the past: from the 1970 s onwards, preventing emigration from mountainous areas was a major national concern, giving rise to the implementation of regional development policies. These policies were exhaustive, with a sectoral focus on agriculture, and emphasis on development of infrastructure. They were successful to a certain extent, and the population of the Alps grew disproportionately in recent decades.

Since the mid 1990s, however, this trend has been reversed and now favors metropolitan areas outside the mountains. New analyses of rural development in Switzerland indicate that in times of economic growth, metropolitan areas benefit at the expense of rural areas, while in times of recession rural areas suffer less than urban areas. But the greater attractiveness of towns is not only the result of stronger economic dynamics at the end of the 1990s or simply of better living conditions there. The sociocultural influence of urban centers is increasing, including new demands for leisure and environmental protection, both of which work against previous ideas about exhaustive development of rural areas. Hence this change is the result of two superimposed processes: general societal change and more dynamic urban economies. And it appears to be fundamental.
This is leading to the decline of both rural areas and small and medium-size towns, particularly in the Alps. As urban behavioral patterns become dominant, the existence of towns is becoming crucial for future regional development. This is especially true for sparsely populated regions within the mountains, where there is a need to avoid greater outmigration.

\section{Commonalities and differences among towns in the Alps}

Although Alpine towns are small, they are not reduced to providing services for their hinterlands and their own inhabitants. In addition to their supply function most towns, independent of their size or economic specialization, share a minimum of external orientation as tourist destinations, by virtue of their export-oriented industries, or due to their political power. This

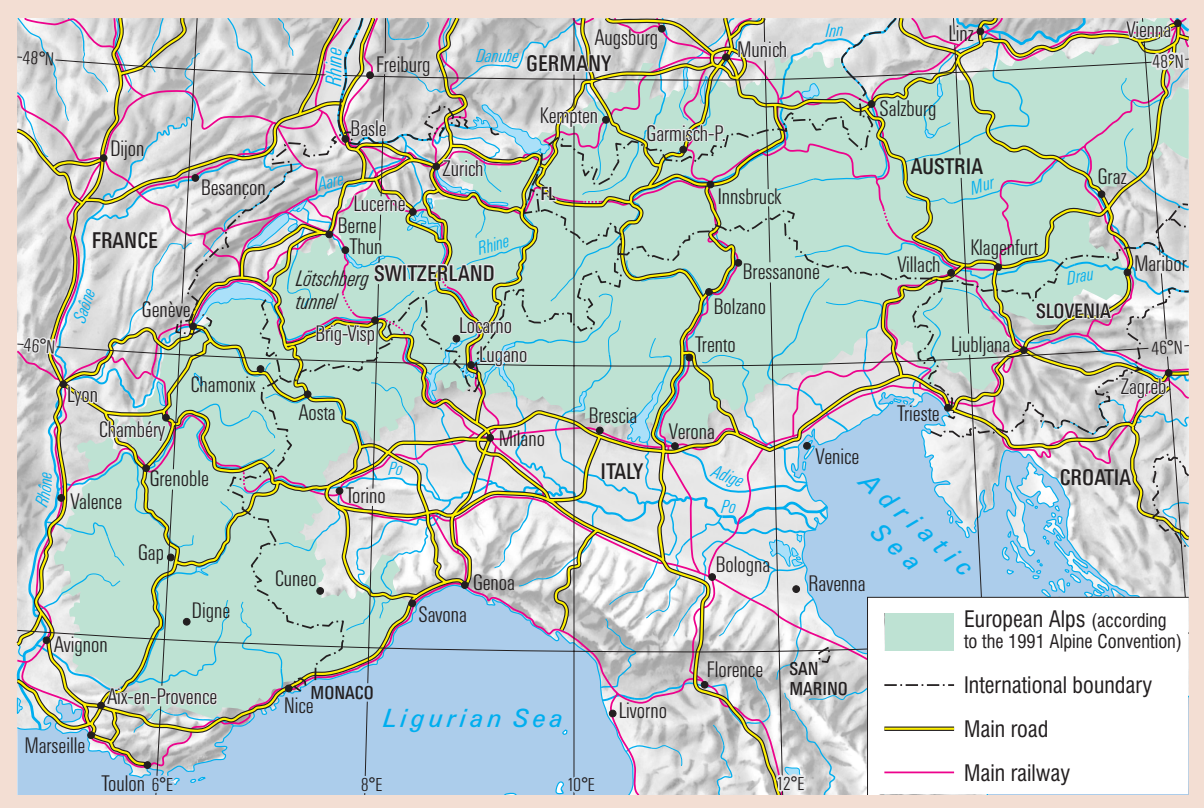

FIGURE 1 Map of the European Alps, with main roads and cities, and smaller urban centers mentioned in this paper. (Map by Andreas Brodbeck) 
TABLE 1 Urban development types in the Alps in 1995, including percentage of population. Types marked with * are discussed in this article.

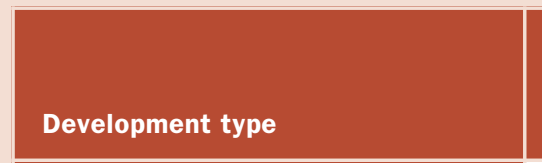

\begin{tabular}{l}
\hline Alpine agglomerations* \\
\hline $\begin{array}{l}\text { Edge cities in perialpine } \\
\text { metropolitan areas* }\end{array}$ \\
\hline
\end{tabular}

Industrial urban areas*

\section{Urban areas with predominant} supply function*

\section{Alpine resorts}

Urban areas with predominant service sector

All urban areas

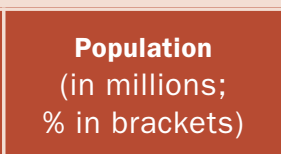

$2.6(29.5)$

$2.5(28.2)$

$1.6(18.2)$

$0.9(10.2)$

$0.4(4.7)$

$0.8(9.2)$

$8.8(100)$

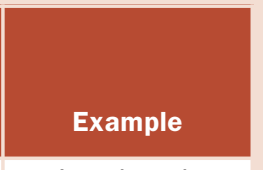

Innsbruck

(Austria)

Thun

(Switzerland)

Brig-Visp

(Switzerland)

Gap

(France)

Chamonix

(France)

Lugano

(Switzerland)
FIGURE 2 Innsbruck, Austria. Municipal works building, designed by architect Lois Welzenbacher in 1926. One of the advantages of Alpine agglomerations is a longstanding history of urban functions, culture and selfimage. (Photo by Manfred Perlik) external orientation means that they produce added value within strategic networks as an essential part of their economy. However, the relationship between this network function and the supply function varies between different types of towns (Table 1). The 4 Alpine towns described below are representatives of the 4 dominant types.

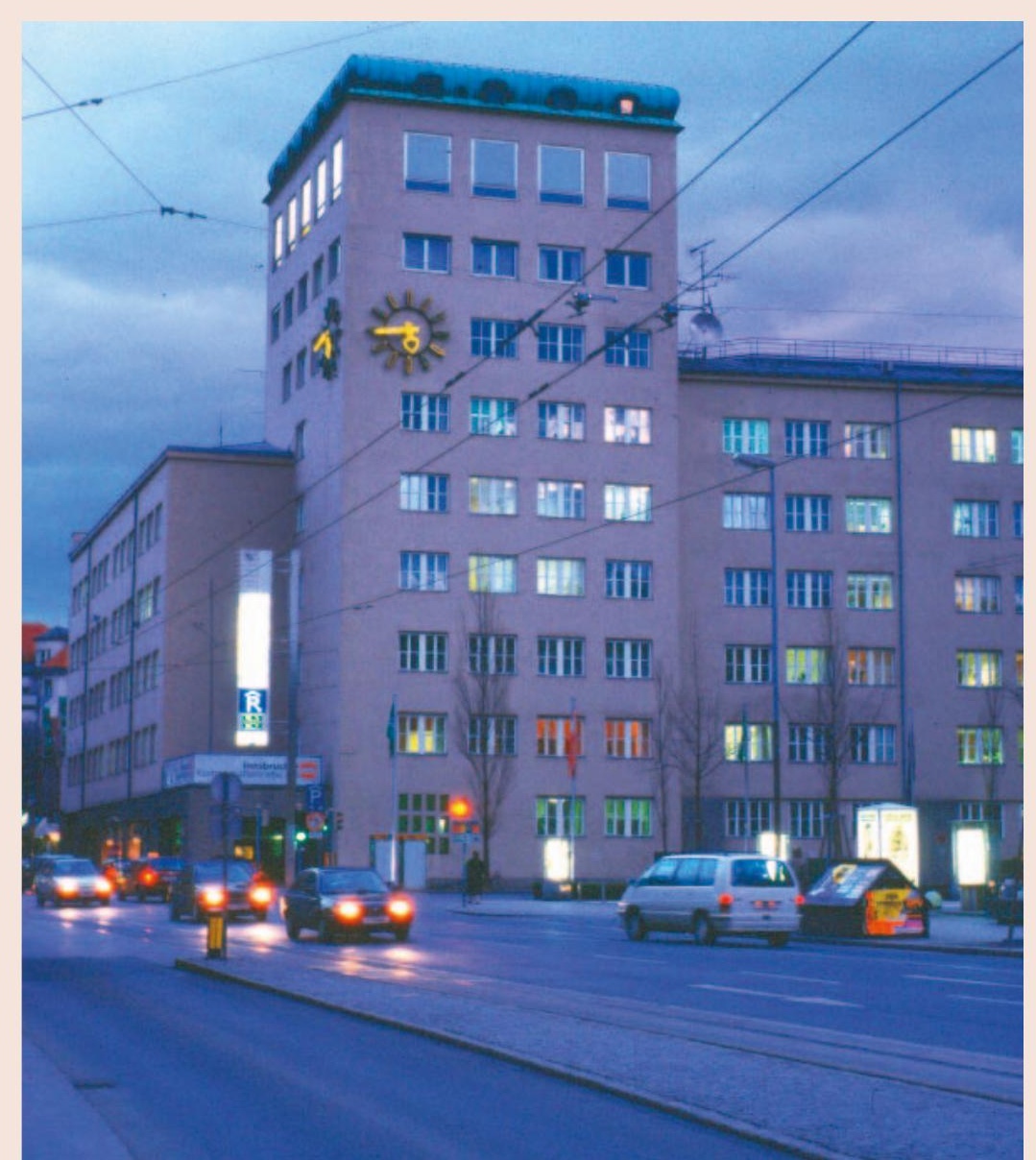

\section{Alpine agglomerations: Innsbruck}

Grenoble, Salzburg, Innsbruck, Bolzano, Trento, Maribor and their agglomerations are comparable to regional capitals outside the Alpine area. These agglomerations are based on various internationally oriented economic activities. They are therefore important at the national level, and to some extent also play an active role in Europeanwide urban competition (Figure 2).

At the end of the 1990s, Innsbruck's citizens refused a third candidacy for the Olympic Games. Paradoxically, this demonstrated an increase in the internationalization of the Austrian town, marked by disengagement from industrial sectors involving the hinterland (tourism and sport) and movement towards a high value-added service industry less dependent on the natural environment. Nevertheless, hinterland-related functions exist to a distinct degree in Innsbruck. Innsbruck made a successful effort to obtain the permanent secretarial headquarters for the Alpine Convention. The university and the university hospitals are regional service providers of international importance. Innsbruck's self-perception reflects the dominance of the externally oriented network function over the supply function; it could be formulated in the following words: "Our production systems are competitive and we have international recognition" (network), and "The hinterland benefits from the strength of the town" (supply).

\section{Edge cities in perialpine metropolitan areas: Thun}

The towns around Alpine borders basically constitute the entry zone to an extended agglomeration or metropolitan region ("edge cities"). They provide basic supplies for their rural hinterlands, and are residential and recreational areas for the metropolitan regions. However, they and their associated hinterlands are also international tourist destinations. They provide minimum standards of urban culture and social services (eg child care) used by locals and commuters, especially those with high levels of qualification.

During the 1990s, the industries that supplied the Swiss army in Thun collapsed. But the labor market in Switzerland's capi- 
tal city, Berne-only about $30 \mathrm{~km}$ away from Thun-has extended well into the Berne agglomeration since then, and the commuting rate from Thun to Berne is now very high. Thun has directed its development accordingly, with construction of residential and retail areas. A new selfimage has also emerged, as shown by attempts to develop the cultural sphere. Nevertheless, this caused considerable difficulties, as the support base for such development is very small, and financial patronage and knowledge are lacking. Dependence on a commercial leisure culture has developed but the dynamics of this culture have not been fully addressed.

Thun's self-image is marked by a realistic view of its heavy dependence on the development of the Berne agglomeration. However, the town is attempting to increase its external orientation to counter its loss of importance (Figure 3). Expressed as a selfassessment: "We are still independent and can play a role in supraregional markets, eg in the recreational or cultural sectors" (network), and "Our urban qualities can attract young professionals as residents” (supply).

\section{Industrial urban areas: Brig-Visp}

Manufacturing systems are as much a part of the social and cultural history of the Alps as agriculture and tourism. They are thus part of the often-noted diversity of the European Alps. Towns with an industrial profile are currently located mainly in the Eastern Alps and along the Italian borders of the Alps. Manufacturing and tourism often coexist in these locations.

In Switzerland, as soon as the new Lötschberg tunnel is built (see Figure 1), Visp will be fully connected to the new Alpine Traversal Railway and will be within commuting distance of Berne. Life will change because of the town's new position in the national railway network and the chemical industry's reorientation from manufacture of bulk goods to biotechnology (Figure 4). Various new options will be available, in research and development, logistics, and tourism, but there will also be a one-sided increase in homes and loss of workplaces.

Self-perception in the Brig-Visp area is characterized by an awareness of its role as a regional center, and a view that national
FIGURE 3 Thun, Switzerland. Informal (and later commercial) transformations of industrial blights into recreational and cultural areas have triggered supraregional ambitions. (Photo by Manfred Perlik)

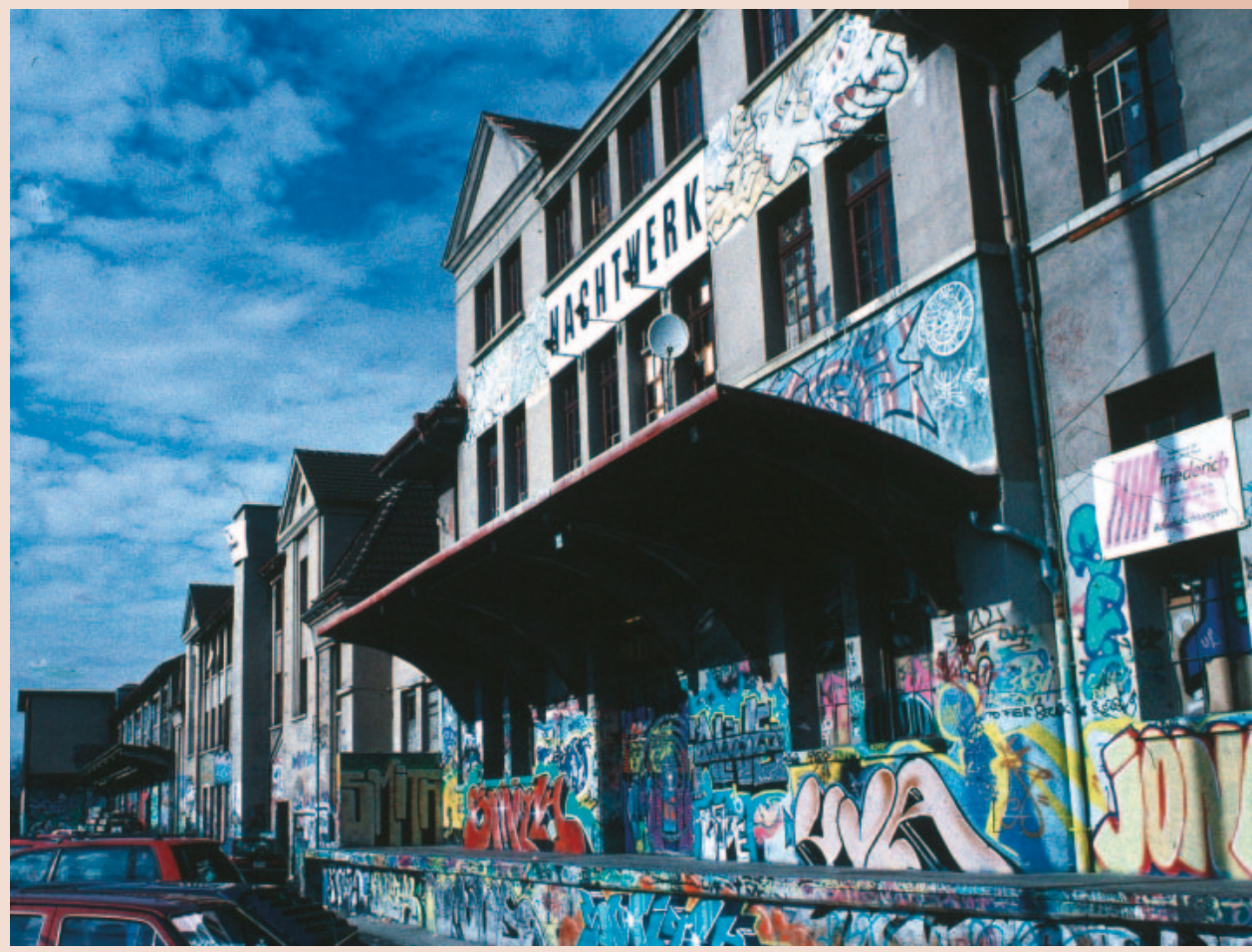

support for this role is justified. On the other hand, there is also an awareness that this role alone will not be sufficient to ensure the regional future. In other words: "Because our production systems are being continually renewed, professional qualifications are increasing and new opportunites are available to young people" (network), and "Local roots, identity, and quality of life still keep people in the

FIGURE 4 Visp, Switzerland. Industrial specialization and better access to major agglomerations also increase the outward orientation of small Alpine towns. (Photo by Manfred Perlik)

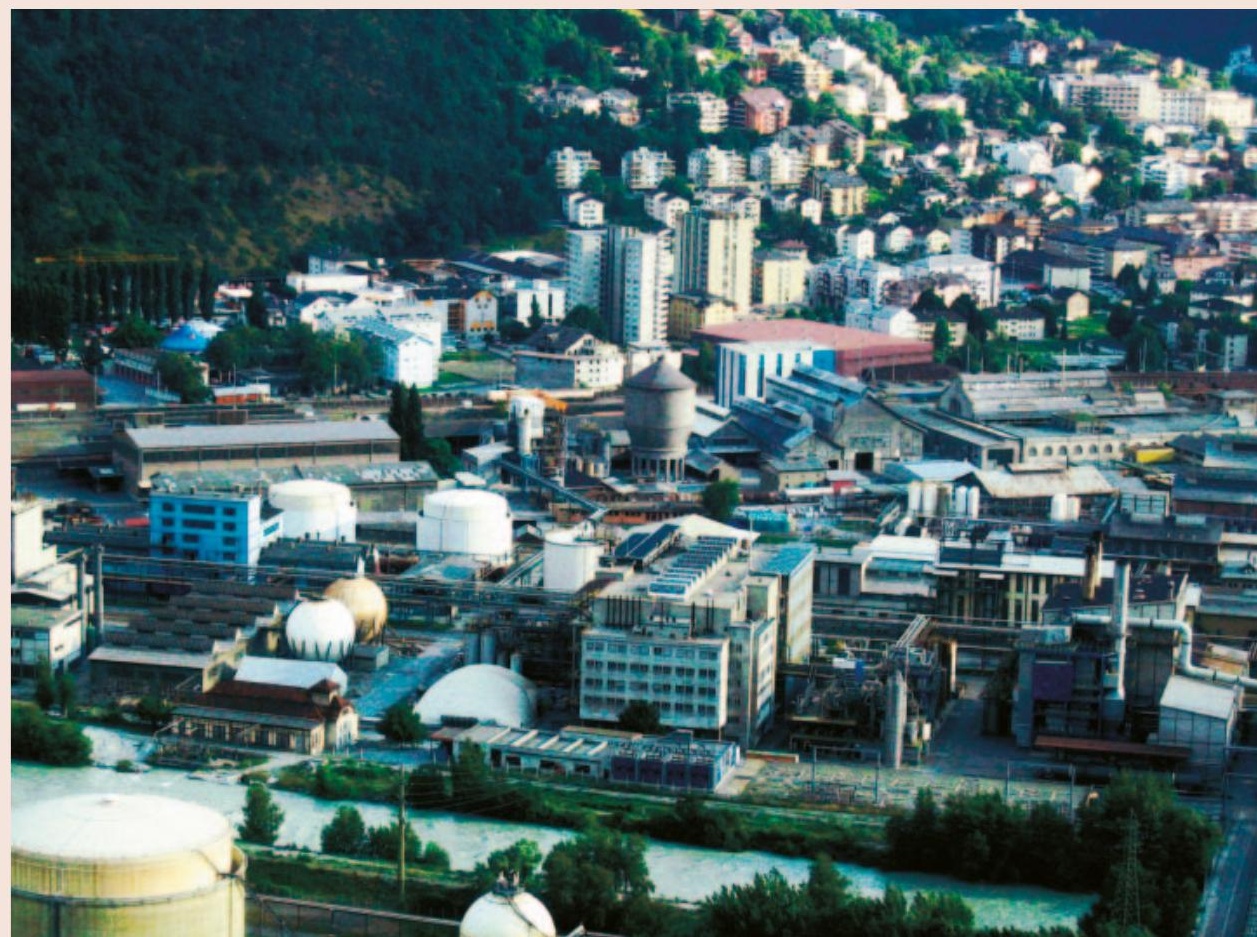




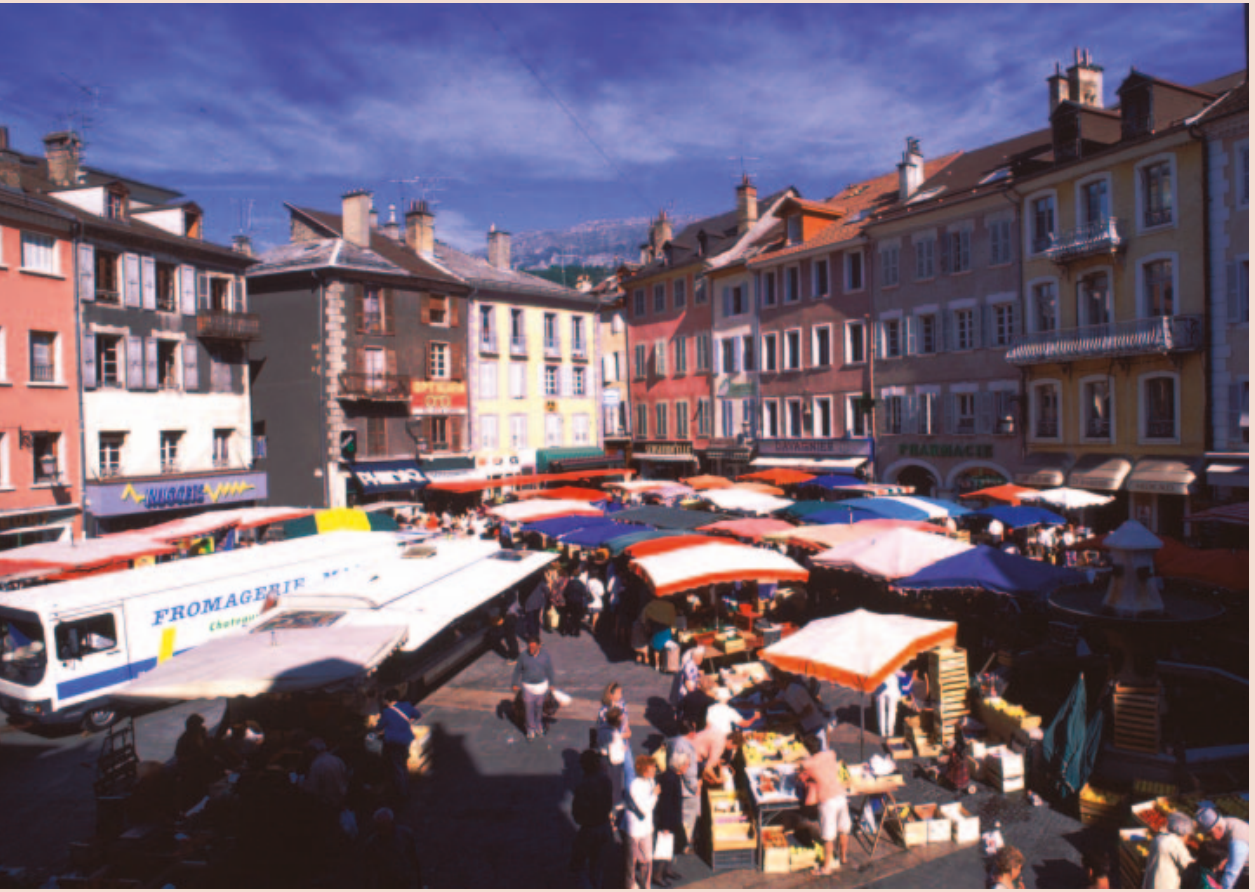

FIGURE 5 Gap, France. Given its dual function in serving the regional population as well as tourists, the local market in Gap offers high quality to both. (Photo by Gerald Lucas) villages; our urban center supports this" (supply).

\section{Urban areas with a predominant supply function: Gap}

The supply function remains dominant in towns such as Gap (France) that are usually located in the center of sparsely populated regions. But external orientation is increasing through in-migration, as a result of quality of life and greater attractiveness for tourism. By the same token, the position and strength of urban infrastructure in towns with a predominant supply function will continue to depend on political decisions regarding spatial organization of the territory and appropriate local services.

Gap is a provincial capital. Industrial parks have recently been rather unsuccessful. Gap's connections to long-distance traffic routes are poor. Nevertheless, the population has increased in recent years. The town benefits by its distance from Grenoble and Aix-en-Provence: because there is no competition far and wide, it has the critical mass for a high level of urban infrastructure (theater, library and cultural services).

Safeguarding of regional functions dominates self-perception in the town of Gap. A certain amount of external orienta- tion is necessary to expand the knowledge base for independent decision-making, and for good local provision of services

(Figure 5). As a self-assessment, this could be reformulated as: "Our town serves a large rural hinterland and must therefore have sufficient polictical weight" (network), and "We need to operate in supraregional networks (culture and tourism) to ensure that the regional population has access to high-quality services" (supply).

\section{Strategies for the future of towns in mountain areas}

The 4 examples above underpin our thesis that towns must always combine internal and external functions, but in varying proportions, depending on the type of town and region. To minimize the risk of losing economic and political power, urban strategies must seek to preserve both functions. The current loss of influence of rural areas, and of small and medium-size towns, makes this conclusion even more important. In order to maintain and develop network and supply functions, common strategic elements should be incorporated by all 4 types of towns:

\section{Strengthening the relationships between towns and their environs}

The hinterlands, especially for small and medium-size towns in the mountains, are a major reason for the existence of a town, by contrast with perialpine agglomerations, for which the mountain environment is first of all a complementary and locational advantage. Hence these towns must maintain close relationships with their hinterlands. Sustainable development is therefore based on the existence of viable towns to prevent outmigration and large-scale division into residential and employment regions. These towns need to move towards adjustment to the urban qualities of towns outside the Alps, while maintaining a strategy that builds on uniqueness.

\section{Developing network and supply functions simultaneously}

Integration of towns into specialized global networks increases the tendency towards territorial de-coupling, since integration makes use only of certain regional 
FIGURE 6 Paths of urbanization in the Alps: development of Alpine agglomerations and differentiation between central places. The 4 examples presented in the paper are colored red.

resources; other potentials are sacrificed For smaller towns in particular, this is a risky decision because regional resources are limited. Urban attractiveness depends ferent qualities. This can only be fostered to a limited extent-it cannot be fully advantage in this regard. Specialization focusing on one function is risky for towns: promoting a town solely as an "international brand" can lead to crisis. Orientation towards a supply function alone leads to

\section{Continuing rather than interrupting the path of development}

It is unrealistic to attempt to attain the added value of production systems outside the Alpine region, because agglomeration advantages are missing. In fact, such an attempt would be counter-productive, since it would consume financial and human resources, and would increase the limits on maneuverability. Figure 6 demonstrates the need for significant backtracking in order to change paths. It therefore seems more sensible to develop existing production systems as far as possible rather than make a complete break, losing traditional competencies and suffering defeat by a new structure. Conversion rather than a complete break means that the different environments of local agents will have to co-exist in close proximity, at least for a while, ie those involved in the old production system will have to have an open attitude towards the new system, and vice veron diversity, density, and a mixture of difplanned. Larger towns have a fundamental dependence on state subsidies.

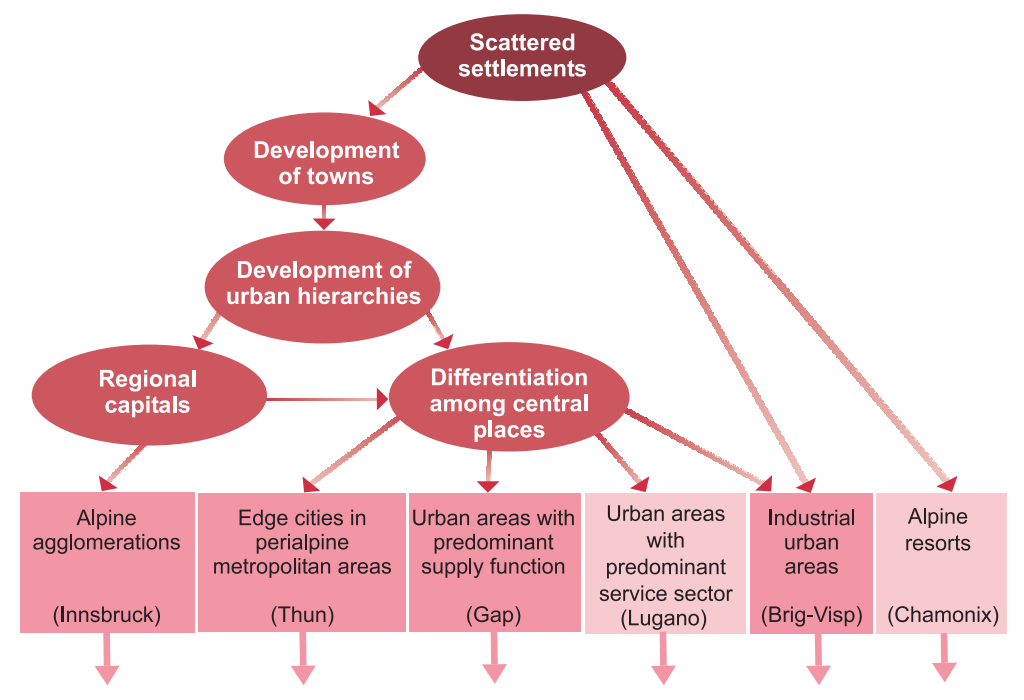

sa. One example of such a system is the watch industry in the Swiss Jura region, which became a micro-electronic industry.

\section{Making the social benefits of a polycentric} system of regional development visible

If a polycentric regional strategy does not allow development of mountainous regions to be financially self-sustaining (even with the acceptance of lower standards), public interest will be needed to maintain fragile regions. Interest of this sort has just been developed in the European Spatial Development Perspective by the European Development Ministers, which recognizes polycentric regional development explicitly as a target in the public interest, and justifies financial compensation for related services.

Manfred Perlik, PhD, specializes in urbanization

\section{ACKNOWLEDGMENTS}

This article is based on the "Alpine Towns Research Project," conducted between 1996 and 2000 at the University of Berne (funded by the Swiss National Science Foundation, SNFS), and the current project entitled "Metropolis Switzerland or a New Polycentric Model of Agglomerations?", conducted within the framework of the Land Resources Management in Peri-Urban Environments research program at the Swiss Federal Institute for Forest, Snow and Landscape Research (WSL), Birmensdorf.

\section{AUTHORS}

\section{Manfred Perlik}

Swiss Federal Institute for Forest, Snow and Landscape Research (WSL), Zürcherstrasse 111, CH-8903 Birmensdorf, Switzerland.

manfred.perlik@wsı.ch processes and the development of rural areas in the countries of the Alpine arc. He does research at the WSL and at the Swiss Federal Institute of Technology in Lausanne. He has worked in European Alpine projects and is currently a member of the Scientific Steering Committee in the transnational "AlpCity" project of the Interreg IIIB program, funded by the European Regional Development Fund.

\section{Paul Messerli}

Institute of Geography, University of Berne, Hallerstrasse 12, $\mathrm{CH}-3012$ Berne, Switzerland. mep@giub.unibe.ch

Paul Messerli is Head of the Department of Human Geography at the University of Berne. He has been instrumental in promoting research on urbanization in the Alps development and regional policy issues. for many years. He is also a political adviser on local

\section{FURTHER READING}

Bätzing W, Perlik M, Dekleva $M$ 1996. Urbanization and depopulation in the Alps. Mountain Research and Development 16:335-350.

Borsdorf A, Paal M, editors. 2000. Die "Alpine Stadt" zwischen lokaler Verankerung und globaler Vernetzung. Institut für Stadt- und Regionalforschung (ISR) Forschungsberichte 20. Vienna: ISR.

Perlik M. 2001. Alpenstädte-Zwischen Metropolisation und neuer Eigenständigkeit. Geographica Bernensia P38. Berne: University of Berne.

Perlik M, Messerli P, Bätzing W. 2001. Towns in the Alps. Mountain Research and Development 21:243-252.

Revue de Géographie Alpine 1999, Vol

87 No 1 edited by Fourny MC, and Vol 87 No 2 edited by Perlik M, Bätzing W. (Thematic issues on urbanization in the Alps).

Schuler M, Perlik M, Pasche N. 2004. Nicht-städtisch, rural oder peripherwo steht der ländliche Raum heute? Analyse der Siedlungs- und Wirtschafsentwicklung in der Schweiz. Berne: Federal Office for Spatial Development (ARE). 